\section{Kirurgisk behandling ved urininkontinens hos barn}

KLINISK OVERSIKT

\section{HANS SKARI}

E-post: hskari@ous-hf.no Avdeling for gastro- og barnekirurgi

Oslo universitetssykehus

Han har bidratt med idé, utforming/design, litteratursøk, utarbeiding og revisjon av manuset og godkjenning av innsendte versjon.

Hans Skari er dr.med., spesialist i generell kirurgi og i barnekirurgi og overlege.

Forfatteren har fylt ut ICMJE-skjemaet og oppgir ingen interessekonflikter.

\section{ANDREAS URDAL}

Avdeling for gastro- og barnekirurgi

Oslo universitetssykehus

Han har bidratt med idé, utforming/design, litteratursøk, utarbeiding og revisjon av manuset og godkjenning av innsendte versjon.

Andreas Urdal er spesialist i generell kirurgi og i barnekirurgi og overlege.

Forfatteren har fylt ut ICMJE-skjemaet og oppgir ingen interessekonflikter.

\section{TRINE SAETHER HAGEN}

Avdeling for gastro- og barnekirurgi

Oslo universitetssykehus

Hun har bidratt med litteratursøk, utarbeiding og revisjon av manuset og godkjenning av innsendte versjon.

Trine Sæther Hagen er spesialist i generell kirurgi, i barnekirurgi og i urologi og overlege. Forfatteren har fylt ut ICMJE-skjemaet og oppgir ingen interessekonflikter.

\section{ANNA BJERRE}

Avdeling for barnemedisin og transplantasjon

Oslo universitetssykehus

Universitetet i Oslo

Hun har bidratt med idé, litteratursøk, utarbeiding og revisjon av manuset og godkjenning av innsendte versjon.

Anna Bjerre er dr.med., spesialist i barnemedisin og seksjonsoverlege.

Forfatteren har fylt ut ICMJE-skjemaet og oppgir ingen interessekonflikter.

\section{GUNNAR AKSNES}

Avdeling for gastro- og barnekirurgi

Oslo universitetssykehus

Han har bidratt med litteratursøk, utarbeiding og revisjon av manuset og godkjenning av innsendte versjon.

Gunnar Aksnes er dr.med., spesialist i generell kirurgi og i barnekirurgi og seksjonsoverlege. Forfatteren har fylt ut ICMJE-skjemaet og oppgir ingen interessekonflikter. 
Bare en liten andel av barn med urinveismisdannelser er inkontinente, men det er viktig å identifisere de barna der kirurgisk behandling kan fjerne eller redusere urinlekkasjen.

Urininkontinens er ukontrollert lekkasje av urin, og hos barn benyttes begrepet fra fem års alder med terminologi og definisjoner utarbeidet av International Children's Continence Society (ICCS) (1,2). Et felles begrepsapparat er viktig, fordi barn med inkontinens behandles av ulike spesialister. Kun i sjeldne tilfeller vil det være en kirurgisk korrigerbar tilstand som er opphavet til inkontinens.

Praktisk tilnærming, utredning og nevrologiske årsaker til urininkontinens hos barn har vært nærmere omtalt i to andre artikler i Tidsskriftet $(2,3)$. I denne artikkelen vil vi omtale de vanligste av en gruppe sjeldne misdannelser som disponerer for urininkontinens: urethraklaffer, ektopisk ureter, blæreekstrofi, epispadi og kloakkekstrofi (tabell 1). Andre sjeldne misdannelser som kan være assosiert med urininkontinens, er sviskemagesyndrom (prune belly syndrome), urogenital sinus og persisterende kloakk. Disse omtales kun summarisk (6-7). Det samme gjelder urininkontinens ved anorektale malformasjoner, etter operasjoner for Hirschsprungs sykdom og sakrococcygealt teratom. Videre skal nevnes etterdryppinkontinens hos jenter, der en del av urinen går inn i vagina ved miksjon, og etterdryppinkontinens hos gutter med uttalt fimose eller urethradivertikkel (8).

\section{Tabell 1}

Typiske symptomer, kliniske funn og funn ved supplerende undersøkelser ved urinveismisdannelser assosiert med urininkontinens (3-5).

\begin{tabular}{|cl|}
\hline Urinveismisdannelser & Beskrivelse \\
\hline Urethraklaffer (hos gutter) & \\
\hline Prenatal ultralydundersøkelse & $\begin{array}{l}\text { Dobbeltsidig utvidelse av samlesystemet } \\
\text { (hydronefrose/hydroureter) og redusert } \\
\text { fostervannsmengde (oligohydramnion) kan } \\
\text { forekomme. Utvidelse av proksimale urethra } \\
\text { (keyhole sign) kan sees }\end{array}$ \\
\hline Symptomer & $\begin{array}{l}\text { Svak kraft på urinstrålen etter fødsel } \\
\text { Febrile urinveisinfeksjon(er) } \\
\text { Eventuelt symptomer og funn forenlig med } \\
\text { nyresvikt } \\
\text { Periodisk urinlekkasje på dagtid og/eller natt }\end{array}$ \\
\hline Klinisk undersøkelse & Normal ytre anatomi og svak kraft på urinstrålen \\
\hline Ultralyd urinveier & $\begin{array}{l}\text { Blærepatologi og dilatert proksimale urethra kan } \\
\text { sees hos noen, utvidelse av samlesystemet på en } \\
\text { eller begge sider og ev. redusert tykkelse og } \\
\text { differensiering av nyreparenkym }\end{array}$ \\
\hline Miksjonsurethrocystografi & $\begin{array}{l}\text { Innsnevring (klaffer) i proksimale urethra, } \\
\text { vesikoureteral refluks bilateralt er vanlig }\end{array}$ \\
\hline Uroflowmetri hos gutter >3 år & Redusert urinstrøm med langtrukken flat kurve \\
\hline Cystoskopi & $\begin{array}{l}\text { Påvisning av urethraklaffer og trabekulær } \\
\text { urinblære }\end{array}$ \\
\hline Ektopisk ureter (kan gi inkontinens & \\
\hline hos jenter) & $\begin{array}{c}\text { Kan påvise hydronefrose og dobbeltanlegg, men } \\
\text { ektopisk ureter kan ikke fremstilles prenatalt }\end{array}$ \\
\hline Prenatal ultralydundersøkelse & $\begin{array}{c}\text { Kan variere hos både gutter og jenter } \\
\text { Kun jenter kan få urininkontinens pga. ektopisk } \\
\text { ureter, og typisk er kontinuerlig dryppeinkontinens } \\
\text { (i tillegg til normale miksjoner). Febrile } \\
\text { urinveisinfeksjon(er) kan forekomme }\end{array}$ \\
\hline Symptomer & $\begin{array}{l}\text { Normal ytre anatomi. Eventuell observasjon av } \\
\text { kontinuerlig dryppeinkontinens }\end{array}$ \\
\hline Klinisk undersøkelse & \\
\hline & \\
&
\end{tabular}




\begin{tabular}{|c|c|}
\hline Urinveismisdannelser & Beskrivelse \\
\hline Ultralyd urinveier & $\begin{array}{l}\text { Kan vise dobbelt nyreanlegg, hydronefrose og } \\
\text { dilatert ureter tilhørende øvre nyreanlegg. Det er } \\
\text { vanligvis ikke mulig å fremstille ektopisk munnende } \\
\text { ureter på ultralyd }\end{array}$ \\
\hline MR urografi & $\begin{array}{l}\text { Kan vise dobbelt nyreanlegg og fremstille at øvre } \\
\text { nyreanleggs ureter munner distalt for } \\
\text { lukkemuskelen eller i vagina. Eventuell annen } \\
\text { tilleggspatologi i øvrige nyreanlegg }\end{array}$ \\
\hline Renografi & Redusert splitfunksjon i affisert øvre nyreanlegg \\
\hline Laparoskopi & $\begin{array}{l}\varnothing v r e \text { nyreanleggs ureter (oftest dilatert) munner } \\
\text { distalt for lukkemuskelen eller i vagina }\end{array}$ \\
\hline \multicolumn{2}{|l|}{ Blæreekstrofi } \\
\hline Prenatal ultralydundersøkelse & $\begin{array}{l}\text { Kan gi mistanke om diagnosen: Det sees } \\
\text { manglende fylning av blæren og en lav } \\
\text { bukveggsdefekt }\end{array}$ \\
\hline Symptomer & $\begin{array}{l}\text { Det nyfødte barnet har vanligvis ingen symptomer. } \\
\text { Det foreligger kontinuerlig urinlekkasje fra } \\
\text { urinblæren }\end{array}$ \\
\hline Klinisk undersøkelse & $\begin{array}{l}\text { Diagnosen kan stilles ved klinisk undersøkelse: Man } \\
\text { ser rett inn på en åpen, liten urinblære og det } \\
\text { foreligger en bukveggsdefekt under navlen. } \\
\text { Bekkenringen er åpen fortil (symfysediastase). } \\
\text { Ved klinisk undersøkelse sees avvikende ytre } \\
\text { kjønnsorganer. } \\
\text { Hos gutter: penis med epispadi. Urethralplate i } \\
\text { stedet for urinrør } \\
\text { Hos jenter: epispadisk urinrørsåpning og todelt } \\
\text { klitoris }\end{array}$ \\
\hline Supplerende undersøkelser & $\begin{array}{l}\text { Er ikke nødvendig for å stille diagnosen, men gjøres } \\
\text { på barnekirurgisk senter }\end{array}$ \\
\hline \multicolumn{2}{|l|}{ Epispadi } \\
\hline Prenatal ultralydundersøkelse & Tilstanden diagnostiseres vanligvis ikke \\
\hline Symptomer & Det nyfødte barnet har vanligvis ingen symptomer \\
\hline Klinisk undersøkelse & $\begin{array}{l}\text { Hos gutter sees urinrørsåpningen på dorsalsiden } \\
\text { av penis, denne kan eventuelt være dekket av } \\
\text { forhud. } \\
\text { Ved komplett epispadi sees en urethralplate med } \\
\text { kontinuerlig urinlekkasje. } \\
\text { Hos jenter sees manglende lukning av urethra og } \\
\text { todelt klitoris. }\end{array}$ \\
\hline Supplerende undersøkelser & $\begin{array}{l}\text { Er ikke nødvendig for å stille diagnosen, men gjøres } \\
\text { på barnekirurgisk senter }\end{array}$ \\
\hline \multicolumn{2}{|l|}{ Kloakkekstrofi } \\
\hline Prenatal ultralydundersøkelse & $\begin{array}{l}\text { Kan gi mistanke om diagnosen: Det sees en lav } \\
\text { bukveggsdefekt (omfalocele) med prolabering av } \\
\text { tarm og manglende blærefylning }\end{array}$ \\
\hline Symptomer & $\begin{array}{l}\text { Det nyfødte barnet vil kort tid etter fødsel utvikle } \\
\text { symptomer på ileus. Pasienten kan ha symptomer } \\
\text { pga. tilleggsmisdannelser }\end{array}$ \\
\hline Klinisk undersøkelse & $\begin{array}{l}\text { Ved nyfødtundersøkelse kan diagnosen stilles ved } \\
\text { klinisk undersøkelse: det sees en bukveggsdefekt } \\
\text { (omfalocele) under navlestedet, prolabering av } \\
\text { tarm (distale ileum) og åpent todelt } \\
\text { urinblæreanlegg med kontinuerlig urinlekkasje. } \\
\text { Bekkenringen er åpen fortil (uttalt } \\
\text { symfysediastase). Ved klinisk undersøkelse sees } \\
\text { avvikende ytre kjønnsorganer og anorektal } \\
\text { malformasjon (manglende anus). Genital anomali } \\
\text { med epispadi, todelt penisanlegg hos gutter }\end{array}$ \\
\hline Supplerende undersøkelser & $\begin{array}{l}\text { Er ikke nødvendig for å stille diagnosen, men gjøres } \\
\text { på barnekirurgisk senter }\end{array}$ \\
\hline Nevrogen blære & \\
\hline
\end{tabular}




\begin{tabular}{|ll|}
\hline Urinveismisdannelser & Beskrivelse \\
\hline Prenatal ultralydundersøkelse & $\begin{array}{l}\text { Kan påvise eller gi mistanke om nevrologiske } \\
\text { misdannelser som hydrocephalus og } \\
\text { ryggmargsbrokk }\end{array}$ \\
\hline Symptomer & Kan variere (3) \\
\hline Klinisk undersøkelse & Ved nyfødtundersøkelse sees evt. ryggmargsbrokk. \\
& Hodeomkrets kan være økt ved hydrocephalus. \\
& Barnenevrologisk undersøkelse: nevrologiske utfall \\
& kan påvises \\
\hline Ultralyd caput & Kan påvise hydrocephalus og annen intrakranial \\
& patologi \\
\hline MR caput/columna & Påvisning av hydrocephalus, ryggmargsbrokk, \\
& spinal dysrafi, kaudalt regresjonssyndrom og andre \\
& tilstander \\
\hline Cystometri & Brukes for å stille diagnosen nevrogen blære \\
\hline
\end{tabular}

Artikkelen er basert på litteratursøk i Pubmed, europeiske og nasjonale retningslinjer og nyere barnekirurgiske lærebøker $(4-7,9)$. Anbefalingene baserer seg også på forfatternes erfaring med kontinensforbedrende kirurgi hos barn og ungdom.

\section{Patofysiologi}

Urinkontinens krever evne til viljestyrt lagring og tømming av urin. Denne evnen forutsetter intakte nervebaner mellom det sentrale og det perifere nervesystemet, urinblæren og sfinkter. I tillegg til intakte nervebaner trengs adekvat blærekapasitet, evne til utvidelse og kontraktilitet i blæren samt at sfinkter er funksjonell og koordinert. En viktig forutsetning for kontinens er et normalt fungerende blæreutløp. Blæreutløpet inkluderer blærehals og proksimale urethra og kan sammenfattes som sfinktermekanismen. Urininkontinens kan altså være et resultat av en eller flere misdannelser/skader på ulike nivå og har opphav i enten en strukturell eller en funksjonell forstyrrelse i blærens kontinensmekanismer. Medfødte misdannelser med strukturelle avvik i urinblæren og blæreutløpet er typisk for pasientene som henvises til kirurgiske inngrep.

\section{Henvisning til barnekirurg}

Det er en diagnostisk utfordring å henvise de riktige pasientene til barnekirurgisk avdeling, og i figur 1 presenteres et flytskjema som kan være til hjelp $(2,3,5)$. Pasientene faller grovt sett i tre kategorier ut ifra alder: barn med prenatalt påvist urinveispatologi, barn med misdannelse påvist ved nyfødtundersøkelse og større barn der foreldrene tar kontakt grunnet urinuhell.

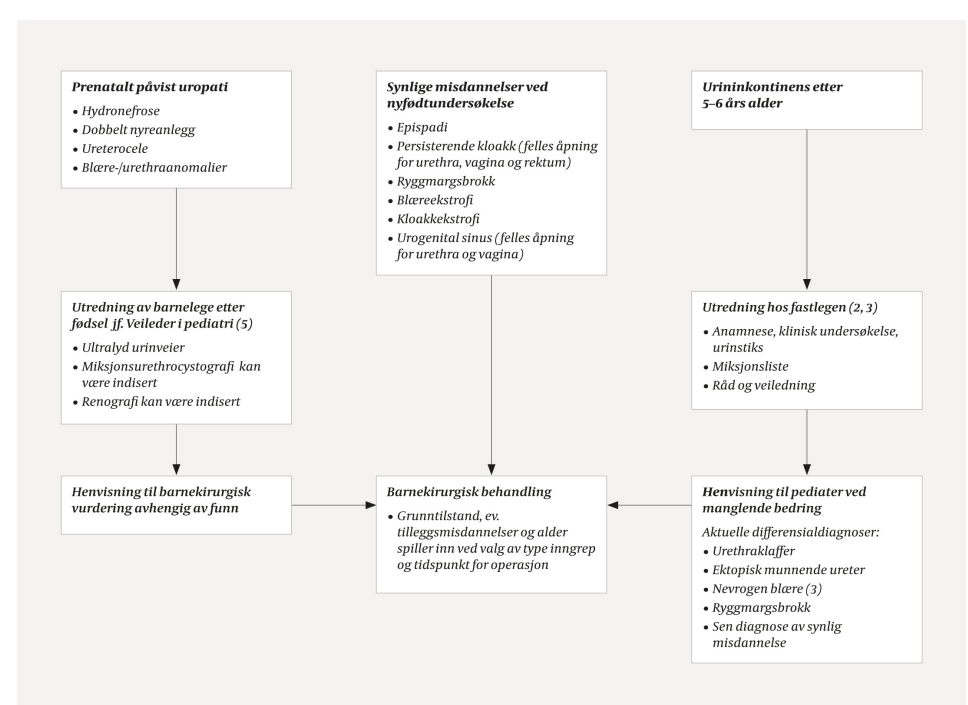

Figur 1 Flytskjema for når et barn med urininkontinens skal henvises til barnekirurgisk avdeling etter henholdvis funn ved ultralyd $i$ svangerskapet, ved nyfødtundersøkelse eller når større barn har urinuhell. Forslagene er basert på forfatternes kliniske erfaring. 
Ved blæreekstrofi, kloakkekstrofi og epispadi stilles diagnosen ved klinisk undersøkelse av det nyfødte barnet. Man kan en sjelden gang se at jenter har manglende åpning(er) nedentil. Det kan dreie seg om anorektal malformasjon (anus ender blindt), persisterende kloakk (en felles åpning for urethra, vagina og rektum) eller urogenital sinus (en felles åpning for urethra og vagina). Barn med slike tilstander har ofte inkontinens.

For større barn med urininkontinens er nøyaktig anamnese, kartlegging av type inkontinens, miksjonslister, nøyaktig klinisk undersøkelse sammenholdt med repeterte uroflowmetriunders $ø$ kelser, ultralyd av urinveier, miksjonsurethrocystografi og eventuell annen bildediagnostikk viktig (2, 9). Selekterte barn med nevrogene blæreforstyrrelser kan ha nytte av kirurgisk behandling, og vanligvis henvises disse fra barnenevrolog (3).

\section{Kontinensforbedrende kirurgi}

Kirurgisk behandling av urininkontinens hos barn har i liten grad vært omtalt i norsk barnekirurgisk litteratur (8). Det kan dreie seg om kirurgisk rekonstruksjon av urinblære, urinrør og sfinktermekanisme, heminefrektomi, transurethral deling av urethraklaffer, botoxinjeksjon i urinblæren og anleggelse av kontinent eller ikke-kontinent urinavledning. Det er teknisk mulig å implantere kunstig sfinkter hos store barn/ungdom, men for å redusere antall komplikasjoner har vi valgt å vente med å implantere kunstig sfinkter til etter puberteten. Disse operasjonene gjøres da i samarbeid med urologene ved Oslo universitetssykehus.

\section{BAKRE URETHRAKLAFFER}

Urethraklaffer er en misdannelse som bare sees hos gutter, og selve klaffene består av vevssegl. Klaffene gir et avløpshinder øverst i urinrøret som hindrer blæretømming og kan i varierende grad skade de øvre urinveiene (figur 2). Tilstanden disponerer for blærefunksjonsforstyrrelse med periodisk urininkontinens (dag/natt). Videre sees urinveisinfeksjoner og vesikoureteral refluks. Urethraklaffer er den vanligste medfødte årsaken (insidens fra 1 per 3 ooo til 1 per 7 ooo) til obstruksjon av blæreutløpet hos nyfødte gutter $(4,10)$.

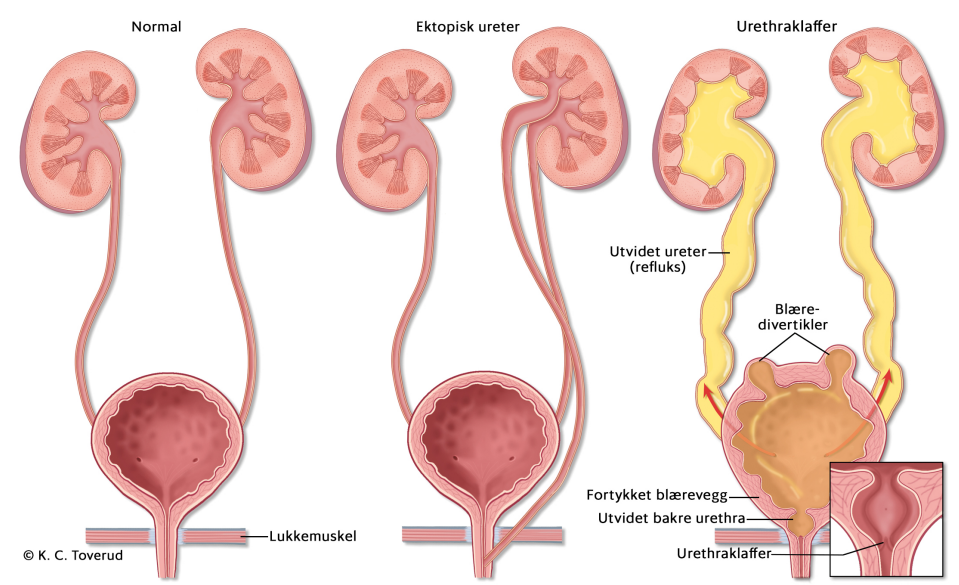

Figur 2 Til venstre illustreres normale anatomiske forhold, $i$ midten venstresidig dobbelt nyreanlegg med ektopisk venstre ureter hos en jente. Hvis ureter munner nedenfor lukkemuskelen, gir dette urininkontinens. Til høyre vises patofysiologiske forandringer ved urethraklaffer: dilaterte proksimale urethra, blceretrabekulering, dobbeltsidig utvidelse av samlesystemet og redusert tykkelse på nyrevevet.

Funn av bilateral hydronefrose ved prenatal ultralyd kan gi mistanke om bakre urethraklaffer, og påvisning av dilatasjon av proksimale urethra (keyhole sign) forsterker mistanken. I de alvorligste tilfellene kan det være lite/manglende fostervann, kombinert lungehypoplasi og nyresvikt (Potters sekvens) og tilstanden kan eventuelt føre til intrauterin fosterd $ø \mathrm{~d}(4,10)$. Barn som prenatalt mistenkes å ha urethraklaffer, bør følges opp av nyfødtlege rett etter fødsel for å få en rask diagnostisk avklaring med ultralyd og miksjonsurethrocystografi. 
Hvis det har vært normale funn på svangerskapsultralyd, kan diagnosen urethraklaffer være vanskelig å stille. Klinisk presentasjon vil avhenge av grad av obstruksjon og pasientens alder. Etter fødsel sees typisk dårlig kraft på urinstrålen, og enkelte barn utvikler pyelonefritt eller urosepsis $(8,9)$. Ved påviste eller mistenkte urethraklaffer avlastes urinblæren med transurethralt eller suprapubisk kateter fram til diagnostisk cystoskopi og eventuell transurethral klaffereseksjon (4).

Hos noen gutter med mildere grad av urethraklaffer stilles diagnosen senere. Disse guttene kan ha kombinert dag-og nattinkontinens som debutsymptom (10). Noen kan ha residiverende urinveisinfeksjoner, og svak urinstråle er typisk. Uroflowmetri viser redusert strømhastighet, avflatet kurve og resturin. Ofte viser ultralyd at disse guttene har fortykket blærevegg, men normale øvre urinveier.

Ved utredning for inkontinens hos gutter bør nøye utfylte drikkelister, miksjonslister, flowmetri, resturin og ultralyd av nyrer inkluderes. Miksjonsurethrocystografi er en ubehagelig unders $ø$ kelse for gutter i denne alderen. Denne gjøres i de tilfellene hvor man mistenker urethraklaffer eller pasienten har hatt residiverende urinveisinfeksjoner, og det gis vanligvis premedikasjon (midazolam) og antibiotikaprofylakse. Typiske funn vil være en forsnevring på klaffestedet, dilatert urethra proksimalt for klaffene og trabekulær blære. Sikker diagnose stilles ved cystoskopi. Hvis diagnosen verifiseres, gjøres transurethral incisjon av klaffene i samme seanse.

Hos noen barn har urethraklaffene bidratt til kontinens. Disse pasientene kan oppleve en forbigående forverring av lekkasjeproblemet etter reseksjon av klaffene (10).

\section{EKTOPISK URETER}

Hvis den nedre (distale) delen av ureter munner på feil sted (utenfor trigonum i blæren), kalles dette ektopisk ureter (figur 2). Dette kan forekomme hos både jenter og gutter, men er langt hyppigere hos jenter og der det foreligger dobbelt nyreanlegg (et øvre og et nedre nyreanlegg). Ektopisk ureter kan hos jenter gi inkontinens dersom den munner distalt for sfinkter (4, 11). Insidens av ektopisk ureter har vært rapportert til 1:1 900 (4).

Ved prenatal ultralyd kan det sees dobbelt nyreanlegg og hydronefrose/hydroureter til ett eller flere anlegg, men det er ikke mulig å stille en definitiv diagnose i svangerskapet. Ved klinisk nyfødtundersøkelse sees ikke patologi. Typisk for disse jentene er kontinuerlig dryppinkontinens dag og natt i tillegg til normale miksjoner, men dette kan være vanskelig å påvise. Hos prepubertale jenter med normale urinveier kan refluks av urin til vagina under miksjon gi lignende symptomer, men da vil lekkasjen oppstå i forbindelse med eller kort tid etter miksjon.

Ultralyd av nyrer vil oftest avdekke et dobbelt nyreanlegg, og som regel er det hydronefrose og dilatert ureter i det øvre nyreanlegget (4). I fravær av dilatasjon kan anlegget være veldig lite og vanskelig å få godt fremstilt ved ultralyd. Best anatomisk fremstilling fås ved MR urografi med kontrast (4). DMSA (dimercaptosuccinic acid)-renografi (nyrescintigrafi) gjøres for å vurdere den relative funksjonen (sidefunksjonen) i høyre versus venstre nyre og for å bestemme funksjonsandelen i øvre versus nedre nyreanlegg. Oftest foreligger et dysplastisk øvre anlegg som dreneres av den ektopiske ureteren. Anlegget har i de fleste tilfeller dårlig funksjon, men produserer likevel nok urin til å gi plagsom lekkasje. Den kirurgiske behandlingen er derfor oftest å fjerne det dysplastiske nyreanlegget og den ektopiske ureteren med åpen eller laparoskopisk heminefrektomi. Dersom funksjonen i anlegget utgjør mer enn $15 \%$ av total nyrefunksjon ved DMSA-renografi, er behandlingen å beholde nyreanlegget og reimplantere det ektopiske ureteret i blæren.

I sjeldne tilfeller er et ektopisk munnende ureter fra en dysplastisk liten nyre uten dobbeltanlegg forklaringen på inkontinens hos jenter. En slik nyre kan være vanskelig å framstille ved bildediagnostikk. Pasientene oppfattes derfor å ha én enkelt, normal nyre, og diagnosen ektopisk ureter stilles ofte seint. Ved en typisk anamnese på ektopisk munnende ureter og funn av én enkelt nyre ved bildediagnostikk må derfor pasienten henvises til en 
barnekirurgisk avdeling for utredning. Fjerning av en slik dysplastisk nyre vil gjøre pasienten kontinent.

\section{BLAEREESTROFI, EPISPADI OG KLOAKKEKSTROFI}

Epispadi, blæreekstrofi og kloakkekstrofi utgjør et kontinuum av alvorlige midtlinjemisdannelser.

Ved komplett epispadi tømmes blæreurinen på en urethralplate på oppsiden av penis, og lukkemuskelen fungerer ikke. Ved mildere former for epispadi munner urinrøret på oppsiden av penis. Ofte har penis en krumning oppover ved denne tilstanden. Insidensen av epispadi i Europa har blitt rapportert til 1: 100 ooo hos gutter og 1:300 ooo hos jenter (5).

Blæreekstrofi er en midtlinjemisdannelse hvor det foreligger en bukveggsdefekt under navlen, urinblæren ligger åpen nederst på buken, bekkenringen er åpen fortil og ytre kjønnsorganer har en misdannelse (epispadi hos gutter og epispadi med delt klitoris hos jenter). Insidensen er 1: 45000 (5).

Kloakkekstrofi er den alvorligste av disse midtlinjemisdannelsene. Det foreligger da en bukveggsdefekt med hinnedekning (omfalocele) under navlen, to urinblæreanlegg, prolabert ileum, åpen bekkenring fortil, misdannelse av ytre kjønnsorganer og manglende anus. Insidensen er 1:316 ooo (5).

Alvorlige tilfeller av misdannelser, slik som blæreekstrofi, kan diagnostiseres med ultralydundersøkelse i svangerskapet ved at det ikke sees fylning av urinblæren og man kan påvise en bukveggsdefekt. Blæreekstrofi og kloakkekstrofi vil være åpenbart fra fødsel. Ved undersøkelse av den nyfødte med blæreekstrofi sees en lav bukveggsdefekt med åpen urinblære og synlig genitalanomali.

Mildere former, som distal epispadi, kan overses ved nyfødtundersøkelse. Urinrørsåpningen ligger på dorsalsiden av penis hos gutter, og man kan finne en spaltet klitoris ved epispadi hos jenter. Meatus og glans hos gutter kan være dekket med forhud. Da selv de mildeste formene for epispadi har en viss grad av symfysediastase og unormalt blæreutløp, er disse pasientene ofte inkontinente og har urinlekkasje som eneste symptom.

Epispadi, blæreekstrofi og kloakkekstrofi krever flere kirurgiske inngrep med rekonstruksjon av urinblære, blærehals og urinrør samt lukning av symfysen (12). Kloakkekstrofi er den mest kompliserte av anomaliene, der også tarmsystemet er affisert (13).

\section{KIRURGI VED NEVROGEN BLAERE}

Ved ryggmargslidelser er inkontinens et resultat av sfinkterdysfunksjon, redusert ettergivenhet i blæreveggen, detrusoroveraktivitet eller en kombinasjon av disse (3, 4). De fleste av disse pasientene blir kontinente og oppnår en trygg situasjon for øvre urinveier (lave trykk og fravær av infeksjoner) med ren intermitterende kateterisering (RIK) alene eller kombinert med blærerelakserende medikamenter og/eller botoxinjeksjon i blæreveggen.

Hos noen er kirurgisk behandling nødvendig for å oppnå kontinens. Den kirurgiske tilnærmingen avhenger av hva som er den viktigste årsaken til lekkasjen, og framfor alt må kirurgien ikke sette øvre urinveier i fare. De fleste barnekirurger og urologer anbefaler å avvente definitiv kirurgi hos yngre barn.

Aktuelle inngrep ved nevrogen blære kan være sfinkterprotese (14), fascieslynge (jenter), forstørrelse av blæren (ileocystoplastikk), kateteriseringskanal og ikke-kontinent urinavledning (poseurostomi) (4).

Hvis problemet er en kombinasjon av nevrogen overaktivitet, stiv blærevegg og sfinkterdysfunksjon, vil man måtte ta hensyn til dette i forkant av anleggelse av sfinkterprotese. Antimuskarinterapi eller tillegg med botoxinjeksjoner i blæreveggen forsøkes i første rekke (3). Pasienter som har fått blæren forstørret med tarm, vil måtte ha 


\section{LITTERATUR:}

1. Austin PF, Bauer SB, Bower W et al. The standardization of terminology of lower urinary tract function in children and adolescents: Update report from the standardization committee of the International Children's Continence Society. Neurourol Urodyn 2016;35: 471-81. [PubMed][CrossRef]

2. Lie A, Gjerstad AC, Fossum V et al. Vannlatingsforstyrrelser hos barn - en praktisk tilnærming. Tidsskr Nor Legeforen 2020; 140. doi:10.4045/tidsskr.18.0565. [PubMed][CrossRef]

3. Aden PK, Gjerstad AC, Skari H et al. Nevrogene blæreforstyrrelser hos barn. Tidsskr Nor Legeforen 2020;140. doi: 10.4045/tidsskr.18.0347. [CrossRef]

4. Radmayr C, Bogaert G, Dogan HS et al. EAU Guidelines on Paediatric Urology. Arnhem: European Association of Urology, 2019.

https://uroweb.org/wp-content/uploads/EAU-Guidelines-on-Paediatric-Urology-2019.pdf Lest 9.9.2019.

5. Cervellione RM, Mantovani A, Gearhart J et al. Prospective study on the incidence of bladder/cloacal exstrophy and epispadias in Europe. J Pediatr Urol 2015; 11: 337.e1-6. [PubMed][CrossRef]

6. Lima M, Manzoni G. red. Pediatric Urology. Milano: Springer, 2015.

7. Coran AG, Caldamone A, Adzick NS et al. red. Pediatric Surgery. 7. utg. Philadelphia, PA: Elsevier Saunders, 2012.

8. Refsum S. Blærefunksjonsforstyrrelser hos barn. Kirurgen 2009; 4: 17-24.

9. Norsk barnelegeforening. Generell veileder i pediatri.

https://www.helsebiblioteket.no/pediatriveiledere?menuitemkeylev1=5962 Lest 9.9.2019.

10. Taskinen S, Heikkilä J, Rintala R. Effects of posterior urethral valves on long-term bladder and sexual function. Nat Rev Urol 2012; 9: 699-706. [PubMed][CrossRef]

11. Roy Choudhury S, Chadha R, Bagga D et al. Spectrum of ectopic ureters in children. Pediatr Surg Int 2008; 24: 819-23. [PubMed][CrossRef]

12. Cuckow PM, Cao KX. Meeting the challenges of reconstructive urology - Where are we now? J

Pediatr Surg 2019; 54: 223-8. [PubMed][CrossRef]

13. Jayman J, Michaud J, Maruf M et al. The dual-staged pathway for closure in cloacal exstrophy:

Successful evolution in collaborative surgical practice. J Pediatr Surg 2019; 54: 1761-5.

[PubMed][CrossRef]

14. Herndon CD, Rink RC, Shaw MB et al. The Indiana experience with artificial urinary sphincters in children and young adults. J Urol 2003; 169: 650-4, discussion 654. [PubMed][CrossRef]

15. Kälble T, Hofmann I, Riedmiller H et al. Tumor growth in urinary diversion: a multicenter analysis. Eur Urol 2011; 6o: 1081-6. [PubMed][CrossRef]

16. Stein R, Zahn K, Huck N. Current indications and techniques for the use of bowel segments in pediatric urinary tract reconstruction. Front Pediatr 2019; 7: 236. [PubMed][CrossRef]

Publisert: 9. mars 2020. Tidsskr Nor Legeforen. DOI: 10.4045/tidsskr.18.0536

Mottatt 21.6.2018, første revisjon innsendt 27.6.2019, godkjent 21.1.2020.

(C) Tidsskrift for Den norske legeforening 2020. Lastet ned fra tidsskriftet.no 